\title{
Influência do silício na suscetibilidade de Spodoptera frugiperda (J.E. Smith) (Lepidoptera: Noctuidae) ao inseticida lufenuron e no desenvolvimento de plantas de milho
}

\author{
Influence of silicon in the susceptibility of Spodoptera frugiperda (J.E.Smith) \\ (Lepidoptera: Noctuidae) to the insecticide lufenuron and in the development of corn plants
}

\author{
Danila Kelly Pereira Neri' ${ }^{I}$ Flávia Batista GomesII Jair Campos Moraes ${ }^{\text {III }}$ \\ Gleidson Bezerra de Góes ${ }^{\mathrm{IV}}$ Saulo de Tarcio Pereira Marrocos ${ }^{\mathrm{IV}}$
}

RESUMO

Com objetivo de avaliar os efeitos do silício na suscetibilidade de Spodoptera frugiperda ao inseticida lufenuron e no desenvolvimento de plantas de milho, foram realizados dois experimentos, sendo um em laboratório e outro em campo. Os tratamentos consistiram de aplicações de ácido silícico associado ou não a diferentes doses do inseticida lufenuron. No experimento conduzido no laboratório, utilizouse o delineamento inteiramente casualizado, em esquema fatorial $2 \times 5$ (com e sem silício $\times$ doses de lufenuron), com cinco repetições. Já o experimento em campo foi em blocos ao acaso, com seis tratamentos, em esquema fatorial $2 \times 3$ (com $e$ sem silício $x$ doses de lufenuron) e quatro repetições. Avaliouse, em laboratório, a mortalidade da lagarta-do-cartucho, tanto às $24 \mathrm{~h}$ e $48 \mathrm{~h}$ antes da aplicação do inseticida, quanto depois da aplicação. Danos ocasionados pela lagarta e as características agronômicas das plantas de milho foram avaliados no experimento de campo. Os resultados demonstraram que o silício interagiu positivamente com o inseticida lufenuron no controle de $\boldsymbol{S}$. frugiperda, em plantas de milho, possibilitando uma redução da dose do inseticida $e$ o fortalecimento da estrutura da planta por aumentar o diâmetro do caule.

Palavras-chave: controle químico, lagarta-do-cartucho, manejo, resistência.

\section{ABSTRACT}

With the objective of evaluating the effects of silicon in the efficiency of the insecticide lufenuron on the control of Spodoptera frugiperda and on the development of corn plants, two experiments were conducted, one being in laboratory and the other in the field. The treatments consisted of applications of silicic acid associated or not with different rates of the insecticide lufenuron. In the laboratory-conducted experiment, the completely randomized design in $2 \times 3$ factorial scheme (with or without silicon $x$ rates of lufenuron) with five replicates was utilized, but the field experiment was in randomized blocks with six treatments in $2 \times 3$ factorial scheme (with and without silicon $x$ dosages of lufenuron) and five replicates. In laboratory, the mortality of fall armyworm, both at 24 and $48 \mathrm{~h}$ before the application of the insecticide and after application, was evaluated. The damages caused by the larvae and the agronomic characteristics of corn plants were also evaluate in the field. The results showed that silicon interacted positively with the insecticide lufenuron in the control of $\boldsymbol{S}$. frugiperda, enabling a reduction of the insecticide dosage and it strengthened the plant structure for increasing the stem diameter.

Key words: chemical control, fall armyworm, management, resistance.

\section{INTRODUÇÃO}

O milho (Zea mays L.) é um cereal muito importante por constituir a base da alimentação humana e da alimentação animal. A produção de milho tende a se expandir fortemente para suprir a demanda gerada pelo consumo de fontes de energia renováveis (SILVA, 2004).

Apesar de estar entre os três maiores produtores, o Brasil não está entre os países com maior nível de produtividade. Segundo GASSEN (1996), um dos fatores do baixo nível de produtividade é a ação de

\footnotetext{
ICentro Federal de Educação Tecnológica/RN, Unidade de Ensino Descentralizada de Ipanguaçu, Povoado Base Física, Zona rural, s/n, 59508-000, Ipanguaçu, RN, Brasil. E-mail: danilaneri@yahoo.com.br. Autor para correspondência.

IDDepartamento de Biologia Animal, Universidade Federal de Viçosa (UFV), Viçosa, MG, Brasil.

IIIDepartamento de Entomologia, Universidade Federal de Lavras (UFLA), Lavras, MG, Brasil.

${ }^{\text {IV } U n i v e r s i d a d e ~ F e d e r a l ~ R u r a l ~ d o ~ S e m i-a ́ r i d o ~(U F E R S A), ~ M o s s o r o ́, ~ R N, ~ B r a s i l . ~}$
} 
insetos-praga e, nesse contexto, destaca-se Spodoptera frugiperda (J.E. Smith) (Lepidoptera: Noctuidae). As lagartas alimentam-se das folhas, diminuindo a área foliar e afetando a capacidade fotossintética da planta e, consequentemente, a produção (SARMENTO et al., 2002). Em ocorrências tardias, pode atacar a espiga e propiciar a entrada de patógenos e umidade (ÁVILA et al., 1997).

O controle de $\boldsymbol{S}$. frugiperda tem sido realizado principalmente pelo uso de produtos químicos. O lufenuron é um inseticida do grupo dos reguladores de crescimento de inseto que apresenta boa eficiência no controle de lagartas, baixa toxicidade para mamíferos e alta seletividade a inimigos naturais (SCHMIDT, 2002). Além disso, o lufenuron, em condições de casa-de-vegetação, apresentou um bom potencial de interação com silício e possibilidades de emprego de subdoses no manejo de $\boldsymbol{S}$. frugiperda (NERI et al., 2005).

O silício, absorvido do solo na forma de ácido silícico, é depositado na parede celular com efeitos benéficos para as plantas e, no caso de problemas fitossanitários, é capaz de aumentar a resistência das plantas ao ataque de insetos e patógenos (EPSTEIN, 2001). Além disso, é capaz de aumentar o teor de clorofila das folhas, o metabolismo das plantas e a tolerância das plantas aos estresses abióticos, diminuir o acamamento e proporcionar ganhos de produtividade (NOJOSA et al., 2006; EPSTEIN, 2001).

Assim, objetivou-se avaliar os efeitos do silício na suscetibilidade de $\boldsymbol{S}$. frugiperda ao inseticida lufenuron e no desenvolvimento de plantas de milho.

\section{MATERIAL E MÉTODOS}

\section{Experimento I}

O experimento foi conduzido na casa-devegetação e no laboratório do Departamento de Entomologia da Universidade Federal de Lavras (UFLA).

Foram semeadas quatro sementes de milho híbrido BRS-3003 Biomatrix ${ }^{\circledR}$ por vaso com capacidade para dois litros de substrato, composto por terra adubada com esterco (2:1) e 4,5g de NPK (4-14-8). Após sete dias da emergência, foi realizado o desbaste deixando-se apenas a plântula mais vigorosa. Os vasos foram dispostos ao acaso sobre bancadas em casa-devegetação.

As plântulas foram adubadas via solo com $75 \mathrm{~mL}$ por vaso de solução aquosa de ácido silícico a $1 \%$ silício sete dias após a emergência, correspondendo a 1 t ha ${ }^{-1}$ de $\mathrm{Sio}_{2}$. Dez dias após a adubação com silício, foram cortadas seções foliares de cada tratamento para serem utilizadas na primeira etapa do experimento. Os tratamentos com inseticida só o receberam na segunda etapa, 12 dias após a aplicação de silício. As diferentes doses do inseticida lufenuron foram diluídas em água, e as seções foliares foram imersas nestas caldas durante cinco segundos e secas naturalmente durante 30 minutos sobre papel filtro.

Foi realizado o teste de preferência sem chance de escolha. Na primeira etapa desse teste, uma seção foliar de $10 \mathrm{~cm}$ de comprimento da quarta folha totalmente expandida das plantas de cada tratamento foi colocada numa placa de Petri $(15 \mathrm{~cm})$, com papel filtro umedecido com água destilada no fundo. Cada placa recebeu 10 lagartas com 24h de idade e, após 24 e 48h da instalação do experimento, foi avaliada a mortalidade por meio da contagem dos sobreviventes. Logo após a última contagem, as lagartas remanescentes desse experimento foram colocadas em novas seções foliares, previamente tratadas com inseticida ou água. Avaliou-se a mortalidade por meio da contagem dos sobreviventes após 24 e $48 \mathrm{~h}$ da instalação dessa segunda etapa do experimento.

Adotou-se o delineamento inteiramente casualizado, em esquema fatorial 2 (com e sem silício) $\times$ 5 (doses de lufenuron), com cinco repetições. Os tratamentos consistiram de: 1) aplicação de silício; 2) aplicação de silício + pulverização com o inseticida lufenuron (Match ${ }^{\circledR} \mathrm{CE}$ ) na dose $15 \mathrm{~g}$ i.a .ha $^{-1}$ (dose recomendada pelo fabricante); 3) aplicação de silício + pulverização com lufenuron na dose $7,5 \mathrm{~g}$ i.a. ha-1; 4) aplicação de silício + pulverização com lufenuron na dose 3,75g i.a. ha-1; 5) aplicação de silício + pulverização com o lufenuron na dose 1,87 g i.a. ha ${ }^{-1}$; 6) pulverização com lufenuron na dose $15 \mathrm{~g}$ i.a. ha ${ }^{-1}$; 7) pulverização com lufenuron na dose $7,5 \mathrm{~g}$ i.a. $\mathrm{ha}^{-1}$; 8) pulverização com lufenuron na dose 3,75 g i.a. ha ${ }^{-1}$; 9) pulverização com o lufenuron na dose $1,87 \mathrm{~g}$ i.a. ha ${ }^{-1}$; 10) testemunha (sem silício e sem inseticida).

Os dados de mortalidade foram transformados em arcosseno $\sqrt{(x / 100)}$ e submetidos à análise de variância, sendo as médias comparadas pelo teste de Scott-Knott $(\mathrm{P} \leq 0,05)$.

\section{Experimento II}

O experimento foi conduzido no período de fevereiro a abril de 2006, no campus da Universidade Federal Rural do Semiárido, situada no município de Mossoró, Rio Grande do Norte (RN).

Foram realizadas uma gradagem, um dia antes do plantio, e duas capinas manuais, sendo a primeira realizada seis dias antes do plantio e a segunda após 28 dias da germinação. 
O silício foi aplicado via solo na forma de solução de ácido silícico a $1 \%$, na quantidade de um $1,0 \mathrm{~L}$ por cova, na primeira aplicação, e $0,6 \mathrm{~L}$ por cova na segunda, correspondendo a 0,5 e $0,33 \mathrm{tha}^{-1}$ de $\mathrm{SiO}_{2}$, respectivamente. As aplicações foram realizadas com o auxílio de um Becker com capacidade para 1L.

A semeadura foi realizada cerca de 12 dias após a primeira chuva. O desbaste foi realizado após 10 dias da germinação, sendo deixadas duas plantas por cova, correspondendo a uma densidade de 50.000 plantas ha ${ }^{-1}$, espaçadas em $1 \mathrm{~m}$ entre linhas e $0,4 \mathrm{~m}$ entre covas. A semente de milho utilizada foi da variedade BR 106 Embrapa. Utilizou-se o sistema de irrigação por microaspersão.

O delineamento experimental foi em blocos ao acaso, com seis tratamentos em esquema fatorial 2 (com e sem silício) $\times 3$ (doses de lufenuron) e quatro repetições, sendo os tratamentos: 1 ) duas aplicações de silício após 10 e 28 dias da emergência; 2) duas aplicações de silício + duas pulverizações com o inseticida lufenuron (Match ${ }^{\circledR} \mathrm{CE}$ ) na dose $15 \mathrm{~g}$ i.a. ha ${ }^{-1}$, após cinco dias das aplicações de silício; 3) duas aplicações de silício + duas pulverizações com lufenuron na dose $7,5 \mathrm{~g}$ i.a. ha ${ }^{-1}$, após cinco dias das aplicações de silício; 4) duas pulverizações com lufenuron na dose $15 \mathrm{~g}$ i.a. ha ${ }^{-1}$; 5) duas pulverizações com lufenuron na dose 7,5g i.a. ha ${ }^{-1}$ e 6 ) testemunha (sem silício e sem inseticida).

Cada parcela experimental foi constituída por 10 plantas de milho distribuídas numa linha de $2 \mathrm{~m}$ de comprimento, separadas por quatro plantas, correspondendo a uma distância entre parcelas de $0,8 \mathrm{~m}$. As parcelas foram demarcadas casualmente e distribuídas em linha, saltando-se uma linha para se iniciar a distribuição das outras parcelas. Para avaliar os danos da praga amostraram-se, de cada parcela, as seis plantas centrais, deixando-se duas plantas de bordadura em cada extremidade, formando uma área útil de $1,2 \mathrm{~m}^{2}$ parcela ${ }^{-1}$. A área total do experimento foi de $158,4 \mathrm{~m}^{2}$.

Quinzenalmente foram realizadas avaliações do ataque da lagarta-do-cartucho utilizando-se uma escala visual de injúrias proposta por DAVIS et al. (1989), sendo a nota de injúria obtida da média das notas de cinco avaliadores. A primeira avaliação foi realizada um dia antes do início das aplicações dos tratamentos, a segunda 14 dias após a primeira aplicação de silício e a terceira avaliação após 10 dias da segunda e da última aplicação de silício.

Quando as plantas completaram 45 dias de idade, foram coletadas para a avaliação da altura das plantas, do número de ramificações dos pendões, do peso da matéria verde, do diâmetro do caule e do número de folhas sadias e danificadas pela lagarta-do-cartucho.
Os dados foram submetidos à análise de variância, e as médias foram comparadas pelo teste de Scott-Knott $(\mathrm{P} \leq 0,05)$.

\section{RESULTADOS E DISCUSSÃO}

Experimento I (casa-de-vegetação)

Não foram encontradas diferenças na percentagem de mortalidade, nas avaliações realizadas durante o período de $24 \mathrm{~h}$ e $48 \mathrm{~h}$ antes da aplicação das diferentes doses do inseticida lufenuron, bem como na avaliação feita 24h depois da aplicação do inseticida nas folhas com e sem silício. As médias gerais observadas foram de 0,8, 1,8 e 5,6\% de lagartas mortas, respectivamente, para as avaliações realizadas 24 e 48 horas antes e 24 horas depois da aplicação (Tabela 1).

Entretanto, na avaliação realizada 48 horas depois da aplicação do inseticida (Tabela 1), foi verificada maior percentagem de mortalidade nos tratamentos que receberam a aplicação do ácido silícico mais a dose de $15 \mathrm{~mL}$ i.a. ha ${ }^{-1}$ e de $7,5 \mathrm{~mL}$ i.a. ha ${ }^{-1}$ do inseticida, sendo a mortalidade média de 94 e 90\%, respectivamente. Os tratamentos com silício e as duas menores doses de lufenuron ( $3,7 \mathrm{~mL}$ i.a. ha ${ }^{-1}$ e $1,8 \mathrm{~mL}$ i.a. $\mathrm{ha}^{-1}$ ) apresentaram uma mortalidade larval superior a $60 \%$ cada. A testemunha que continha somente silício foi a que ocasionou a menor mortalidade do insetopraga, aproximadamente $2 \%$.

No que diz respeito à porcentagem de mortalidade larval de $\boldsymbol{S}$. frugiperda expostas às folhas que receberam apenas o inseticida, também foi constatado que o tratamento que continha a maior dose foi o que provocou uma maior mortalidade superior a 90\% (Tabela 1). Entretanto, os tratamentos nas doses de $7,5 \mathrm{~mL}$ i.a. ha $^{-1}$ e $3,7 \mathrm{~mL}$ i.a. ha ${ }^{-1}$ ocasionaram uma mortalidade inferior à dose completa do inseticida, porém causaram uma mortalidade larval em torno de 54 e 60\%, respectivamente. Já a menor dose do inseticida $\left(1,8 \mathrm{~mL}\right.$ i.a. $\left.\mathrm{ha}^{-1}\right)$ não diferiu da testemunha, com mortalidade larval inferior a $25 \%$.

Ao se comparar o efeito das doses de lufenuron isoladamente na presença ou ausência de silício, constatou-se que o tratamento que recebeu a meia dose $\left(7,5 \mathrm{~mL}\right.$ i.a. $\left.\mathrm{ha}^{-1}\right)$ provocou maior mortalidade nas lagartas quando interagido com o silício, ou seja, $40 \%$ a mais do que na ausência da aplicação de ácido silícico nas plantas. O mesmo foi constatado quando se utilizou a menor dose $\left(1,8 \mathrm{~mL}\right.$ i.a. ha $\left.{ }^{-1}\right)$ e, nesse caso, a interação silício $\times$ inseticida provocou uma mortalidade de, aproximadamente, $65 \%$ maior em relação ao efeito isolado de lufenuron. 
Tabela 1 - Porcentagem de mortalidade de $\boldsymbol{S}$. frugiperda (média \pm erro padrão) 48 horas após a aplicação do inseticida lufenuron, em folhas de plantas com e sem a aplicação de silício. Lavras. 2005.

\begin{tabular}{|c|c|c|}
\hline \multirow{2}{*}{ Inseticida (dosagens) } & \multirow[b]{2}{*}{ Sem silício } & \multirow[b]{2}{*}{ Com silício } \\
\hline & & \\
\hline Inseticida (15mL i.a. ha $\left.{ }^{-1}\right)$ & $92 \pm 1,7 \mathrm{aA}$ & $94 \pm 1,8$ aA \\
\hline Inseticida $\left(7,5 \mathrm{~mL}\right.$ i.a. ha $\left.{ }^{-1}\right)$ & $54 \pm 5,8$ bB & $90 \pm 1,4 \mathrm{aA}$ \\
\hline Inseticida (3,7mL i.a. ha $\left.{ }^{-1}\right)$ & $60 \pm 1,4 \mathrm{bA}$ & $62 \pm 5,2 \mathrm{bA}$ \\
\hline Inseticida $\left(1,8 \mathrm{~mL}\right.$ i.a. ha $\left.{ }^{-1}\right)$ & $22 \pm 1,7 \mathrm{cB}$ & $64 \pm 6,4 \mathrm{bA}$ \\
\hline Testemunha & $00 \pm 0,0 \mathrm{cA}$ & $02 \pm 0,9 \mathrm{cA}$ \\
\hline CV (\%) & \multicolumn{2}{|c|}{32,39} \\
\hline
\end{tabular}

Médias seguidas de mesma letra minúscula, na coluna, e maiúscula, na linha, não diferem entre si, respectivamente, pelo teste $\mathrm{F}$ e pelo teste de Scott-Knott $(\mathrm{P}=0,05)$. (Inseticida $\mathrm{F}=42,021 ; \mathrm{P}>\mathrm{F}=<0,0001 ; \mathrm{GL}=4$; Silício $\mathrm{F}=12,293 ; \mathrm{P}>\mathrm{F}=0,0011 ; \mathrm{GL}=1 ;$ Inseticida*Silício $\mathrm{F}=$ 3,617; $\mathrm{P}>\mathrm{F}=0,0131 ; \mathrm{GL}=4)$.

\section{Experimento II (campo)}

As notas atribuídas às injúrias devido à alimentação de $\boldsymbol{S}$. frugiperda em plantas de milho na primeira e na terceira avaliação não apresentaram diferenças significativas entre os tratamentos, cujas médias gerais foram de 6,9 e 3,7, respectivamente.

Na segunda avaliação (Tabela 2), verificouse, para a dose total do lufenuron, uma interação negativa com o silício, apresentando um dano médio de aproximadamente 5,5. Entretanto, foram encontradas as menores notas de injúrias nas plantas que receberam o silício mais inseticida na sua meia dose $(7,5 \mathrm{~mL} \mathrm{ia} \mathrm{ha-1})$.

No que se refere às notas de injúrias nos tratamentos apenas com inseticida, foram observadas diferenças entre elas. Além disso, as plantas pulverizadas com lufenuron nas suas duas doses apresentaram menores notas, ou seja, foram menos injuriadas pelas lagartas do que a testemunha sem

Tabela 2 - Notas de injúrias de lagartas $\boldsymbol{S}$. frugiperda (média \pm erro padrão) em plantas de milho que receberam os diferentes tratamentos, após 14 dias da aplicação de silício. Mossoró. 2006.

\begin{tabular}{lcc}
\hline \multirow{2}{*}{ Inseticida (dosagens) } & \multicolumn{2}{c}{-------- Nota de injúria--------- } \\
& Sem silício & Com silício \\
\hline Inseticida (15mL i.a. ha $\left.{ }^{-1}\right)$ & $4,2 \pm 0,1 \mathrm{bB}$ & $5,5 \pm 0,2 \mathrm{aA}$ \\
Inseticida (7,5mL i.a. ha $\left.{ }^{-1}\right)$ & $4,5 \pm 0,2 \mathrm{bA}$ & $4,0 \pm 0,1 \mathrm{bA}$ \\
Testemunha & $5,5 \pm 0,2 \mathrm{aA}$ & $6,0 \pm 0,1 \mathrm{aA}$ \\
CV (\%) & \multicolumn{2}{c}{12,0} \\
\hline
\end{tabular}

Médias seguidas de mesma letra minúscula, na coluna, e maiúscula, na linha, não diferem entre si, respectivamente, pelo teste $\mathrm{F}$ e pelo teste de Scott-Knott $(\mathrm{P}=0,05)$. (Inseticida $\mathrm{F}=$ 12,874; $\mathrm{P}>\mathrm{F}=0,0006 ; \mathrm{GL}=2$; Silício $\mathrm{F}=2,953 ; \mathrm{P}>\mathrm{F}=0,1063$; $\mathrm{GL}=1$; Inseticida*Silício $\mathrm{F}=4,370 ; \mathrm{P}>\mathrm{F}=0,0320 ; \mathrm{GL}=2$ ). inseticida e sem silício, que se mostrou aproximadamente $23 \%$ mais injuriada.

Quando se comparou o efeito das doses de lufenuron isoladamente, na presença ou ausência de silício, constatou-se que os danos ocasionados às plantas do tratamento que recebeu pulverizações do inseticida na dose de $15 \mathrm{~mL}$ i.a ha ${ }^{-1}$ foram maiores quando as plantas também receberam silício. O mesmo resultado não foi encontrado na dose de $7,5 \mathrm{~mL}$ ia ha ${ }^{-1}$ e na testemunha, que apresentaram danos semelhantes, independentemente da aplicação ou não do silício.

Em relação aos efeitos da interação silício e inseticida no desenvolvimento de plantas de milho, os números de folhas sadias e danificadas pela lagartado-cartucho não apresentaram diferenças significativas nos tratamentos com inseticidas, com um valor médio de 3,7 para o número de folhas sadias e 6,4 para as danificadas. Contudo, resultados diferentes foram encontrados entre os tratamentos que receberam ou não silício (Tabela 3). Nesse caso, foi maior o número de folhas sadias nas plantas com silício. No entanto, o número de folhas danificadas não se mostrou diferente na presença ou na ausência das aplicações de ácido silícico.

Os dados referentes às características agronômicas da cultura do milho não foram diferentes nos tratamentos com inseticida. Esses tratamentos apresentaram um valor médio de $46,5 \mathrm{~cm}$ para o tamanho das plantas, 1,4cm para o diâmetro, 3,6 para o número de ramificações do pendão e 116,3g para o peso verde das plantas. Todavia, as plantas que receberam aplicações de ácido silícico mostraram diferenças significativas no diâmetro do caule (Tabela 3), sendo maiores nas plantas com silício. Para os demais parâmetros, não foram observadas respostas da aplicação do ácido silícico. 
Influência do silício na suscetibilidade de Spodoptera frugiperda (J.E. Smith) (Lepidoptera: Noctuidae)...

Tabela 3 - Tamanho, diâmetro do caule, número de pendão, peso verde da parte aérea, número de folhas sadias e danificadas por $\boldsymbol{S}$. frugiperda (média \pm erro padrão) de plantas de milho tratadas ou não com silício. Mossoró. 2006.

\begin{tabular}{ccccccc}
\hline Tratamentos & Tamanho $(\mathrm{cm})$ & Diâmetro $(\mathrm{cm})$ & No pendão & Peso (g) & № folhas sadias & № folhas danificadas \\
\hline Com silício & $49,4 \pm 1,4 \mathrm{a}$ & $1,50 \pm 0,01 \mathrm{a}$ & $4,3 \pm 0,3 \mathrm{a}$ & $129,7 \pm 4,7 \mathrm{a}$ & $4,3 \pm 0,1 \mathrm{a}$ \\
Sem silício & $43,6 \pm 1,7 \mathrm{a}$ & $1,30 \pm 0,02 \mathrm{~b}$ & $2,8 \pm 0,2 \mathrm{a}$ & $103,0 \pm 5,2 \mathrm{a}$ & $3,2 \pm 0,1 \mathrm{~b}$ & $6,2 \pm 0,1 \mathrm{a}$ \\
CV $(\%)$ & 45,0 & 16,6 & 84,4 & 56,3 & 24,0 & 29,5 \\
\hline
\end{tabular}

Médias seguidas de mesma letra minúscula, na coluna, não diferem entre si pelo teste $\mathrm{F}$ e pelo teste de $\mathrm{Scott}-\mathrm{Knott}(\mathrm{P}=0,05)$. (Tamanho $\mathrm{F}=$ 0,470; $\mathrm{P}>\mathrm{F}=0,5033 ; \mathrm{GL}=1$; Diâmetro $\mathrm{F}=4,885 ; \mathrm{P}>\mathrm{F}=0,0430 ; \mathrm{GL}=1 ;$ № Pendão $\mathrm{F}=1,445 ; \mathrm{P}>\mathrm{F}=0,2479 ; \mathrm{GL}=1 ; \mathrm{Peso} F=0,996 ; \mathrm{P}>\mathrm{F}$ $=0,3340 ; \mathrm{GL}=1 ; \mathrm{N}^{\mathrm{o}}$ folhas sadias $\mathrm{F}=8,346 ; \mathrm{P}>\mathrm{F}=0,0112 ; \mathrm{GL}=1 ; \mathrm{N}^{\mathrm{o}}$ folhas danificadas $\mathrm{F}=0,152 ; \mathrm{P}>\mathrm{F}=0,7019 ; \mathrm{GL}=1$ ).

O silício em laboratório proporcionou um efeito positivo na mortalidade larval de $\boldsymbol{S}$. frugiperda, quando interagido com o inseticida lufenuron nas doses de 7,5mL i.a. ha ${ }^{-1}$ e 1,8mL i.a. ha-1 ${ }^{-1}$ que correspondem, respectivamente, à metade e a um oitavo da dose recomendada. Resultados semelhantes foram encontrados por NERI et al. (2005), ao avaliarem a interação do silício com lufenuron no manejo de $\boldsymbol{S}$. frugiperda em casa-de-vegetação. Nesta pesquisa, 48 horas após a liberação das lagartas sobre as folhas de milho, foi observada uma maior mortalidade no tratamento que continha silício (via solo) e lufenuron em meia dose (7,5g i.a. ha $\left.{ }^{-1}\right)$.

A elevada percentagem de mortalidade das lagartas presentes nas plantas que receberam inseticidas se deve à alta eficiência do inseticida lufenuron, o que confirma o estudo de GOMEZ \& ÁVILA (2001), quando afirmam que os inseticidas reguladores de crescimento podem controlar eficientemente as lagartas de $\boldsymbol{S}$. frugiperda.

Em campo, as plantas na presença de silício que foram pulverizadas com lufenuron na sua meia dose $(7,5 \mathrm{~mL}$ i.a. ha-1) foram menos injuriadas, apresentando, nesse caso, perfurações arredondadas e lesões em algumas folhas. Resultados semelhantes foram encontrados por NERI et al. (2005), os quais constataram um efeito positivo da interação, a qual possibilitou a redução da dose do inseticida pela metade.

As plantas que receberam somente silício apresentaram grandes lesões em várias folhas, provocadas pela lagarta-do-cartucho. Essas lesões provavelmente se devem à migração desse inseto-praga das plantas susceptíveis para as resistentes, devido à alta infestação dessa praga em todo o experimento, o que, possivelmente, provocou uma quebra de resistência (WILLIAMS et al, 1978). Portanto, não se exclui a possibilidade de as plantas que receberam somente o silício mostrarem-se resistentes em outras condições ambientais.
Em relação aos caracteres agronômicos das plantas de milho, o aumento do diâmetro das plantas que receberam o silício deve-se ao seu acúmulo nos tecidos de suporte/sustentação do caule, o que fortalece substancialmente a estrutura da planta (PLUCKNETT, 1971). Já o maior número de folhas sadias nas plantas com silício deve-se provavelmente à recuperação das plantas induzidas pelo silício, tornando-as tolerantes ao ataque da praga. No entanto, isso não ocorreu para o número de folhas danificadas devido à alta infestação no início do experimento, que ocasionou elevados níveis de injúrias em todos os tratamentos.

Apesar de o silício proporcionar maior peso seco por unidade de área foliar, aumentar os pesos secos e frescos das raízes e desempenhar um importante papel no crescimento das plantas (EPSTEIN, 1994), sua influência não foi constatada no tamanho e no peso verde das plantas de milho neste experimento. Resultados semelhantes foram encontrados por SILVA \& BOHNEN (2001), segundo os quais não foram encontradas diferenças entre a adição ou não de silício na produção de matéria seca da parte aérea e das raízes, bem como no rendimento de grãos de plantas de arroz (Oryza sativa L.) em solução nutritiva.

No que se refere ao número de ramificações do pendão, o silício também não exerceu nenhuma influência, provavelmente devido ao intenso ataque da lagarta-do-cartucho na fase inicial da cultura, uma vez que todas as folhas e espigas que a planta eventualmente produzirá estão sendo formadas no estágio fisiológico “V3”, podendo-se dizer, portanto, que o estabelecimento do número máximo de grãos ou a definição da produção potencial estão sendo definidos nesse estádio (MAGALHÃES \& DURÃES, 2006).

O elevado índice populacional de $\boldsymbol{S}$. frugiperda no experimento realizado no Município de Mossoró deve-se à alta temperatura, associada à baixa precipitação pluviométrica, que favoreceu a alta incidência da praga, ou seja, acima do nível de controle, 
que é de $20 \%$ de plantas com folhas raspadas (DIDONET et al., 2000) no período inicial de desenvolvimento da cultura.

\section{CONCLUSÃO}

O silício interage positivamente com o inseticida lufenuron no controle de $\boldsymbol{S}$. frugiperda em plantas de milho, proporcionando uma redução da dose do inseticida e aumentando a eficiência do controle de S. frugiperda.

O silício, apesar de não afetar o tamanho da planta, o peso da matéria verde e o número de ramificações do pendão, fortalece a estrutura da planta de milho por aumentar o diâmetro do caule.

\section{REFERÊNCIAS}

ÁVILA, C.J. et al. Insetos pragas: reconhecimento, comportamento, danos e controle. In: ______. Milho, informações técnicas. Dourados: Embrapa-CPAO, 1997. p.157-181. (Embrapa-CPAO. Circular Técnica, 5).

DIDONET, J. et al. Incidência e densidade populacional de Spodoptera frugiperda (Lepidóptera, Noctuidae) na cultura do milho, em Gurupi-To. Bioscience Journal, v.16, n.2, p.1723, 2000.

EPSTEIN, E. Silicon in plants: facts vs concepts. In: Silicon in agriculture. The Netherlands: Elsevier Science, 2001. 403p.

EPSTEIN, E. The anomaly of silicon in plant biology. Proceedings National of Academy Science, v.91, n.1, p.1117, 1994.

GASSEN, D.N. Manejo de pragas associadas à cultura do milho. Passo Fundo: Aldeia Norte, 1996. 134p.

GOMEZ, S.A.; ÁVILA, C.J. Controle químico da lagartado-cartucho, Spodoptera frugiperda (Smith, 1792), na cultura do trigo. Dourados: Embrapa Agropecuária Oeste, 2001. 18p. (Boletim de Pesquisa e Desenvolvimento).

MAGALHÃES, P.C.; DURÃES, F.O.M. Ecofisiologia. Disponível em: <http://www.cnpms.embrapa.br/publicacoes/ milho/ecofisiologia.htm\#v3>. Acesso: (25/07/2006).

NERI, D.K.P. et al. A interação silício com inseticida regulador de crescimento no manejo da lagarta-do-cartucho Spodoptera frugiperda (J. E. Smith, 1797) (Lepidoptera: Noctuidae) em milho. Ciência e agrotecnologia, v.29, n.6, p. 1167-1174, 2005.

NOJOSA , G.B.A. et al. Uso de fosfitos e silicatos na indução de resistência. In: _. Indução de resistência em plantas a patógenos e insetos. Piracicaba: FEALQ, 2006. p. 139153.

PLUCKNETT, D.L. The use soluble silicates in Hawalian agriculture. University of Queensland. v.1, n.6, p.203-223, 1971.

SARMENTO, R. de A. et al. Revisão da biologia, ocorrência e controle de Spodoptera frugiperda (Lepidóptera, Noctuidae) em milho no Brasil. Bioscience Journal, v.18, n.2, p.41-48, 2002.

SCHMIDT, F.B. Linha básica de suscetibilidade de Spodoptera frugiperda (Lepidóptera: Noctuidade) a Lufenuron na cultura do milho. 2002. 48f. Dissertação (Mestrado em Entomologia) - Escola Superior de Agricultura Luiz de Queiroz, Piracicaba, SP.

SILVA, L.S.; BOHNEN, H. Rendimento e acúmulo de nutrientes pelo arroz em solução nutritiva com e sem adição de silício. Revista Brasileira de Ciência do Solo, v.25, n.3, p.771777, 2001.

SILVA, M.T.B. da et al. Reação de cultivares e eficiência do controle químico de pulgões vetores do Barley yellow dwarf virus em trigo. Ciência Rural, v.34, n.5, p.1333-1340, 2004.

VENDRAMIM, J.D. A resistência de plantas e o manejo de pragas. In: Manejo integrado de pragas. São Paulo: UNESP, 1990. p.177-197. 